meet, they will become tightly associated. In abetalipoproteinaemia it may be that a microsomal triglyceride transfer protein which forms a dimer with protein disulphide isomerase, the ER enzyme responsible for the correct arrangement of disulphide bridges, may be absent ${ }^{14}$. These results are consistent with a model for the assembly of triglyceride-rich VLDL (very-low-density lipoprotein) particles and $\operatorname{Lp}(a)$ in which disulphide formation and lipidation are cotranslational events. Do apoB-100 and $\operatorname{apo}(a)$ associate at this early stage or later in the secretory pathway?

The transgenic mice of Lawn and colleagues $^{1}$ show for the first time that free circulating apo $(a)$ can lead to atheroma, fat deposits, on a high-fat diet. The lesions in the mouse, a species not normally susceptible to atheroma, closely resemble the human disease in consisting of lipid-rich fibrous plaques. This begs the questions of how the atherosclerosis is caused, and what the normal function of $\mathrm{Lp}(a)$ is.

It may be the $\operatorname{Lp}(a)$ adds an extra control to fibrinolysis by competing for the binding of plasminogen to its endothelial cell receptor, thereby blocking the activity of tissue plasminogen activator, when in excess it would induce a procoagulant state ${ }^{8}$. However, $\operatorname{Lp}(a)$ binds avidly to tissue matrix components, including glycosaminoglycans, fibronectin, collagen and fibrin.

The presence of apo $(a)$ with apoB-100 in atherosclerotic plaques (see figure) and the binding of kringle IV to fibrin has led to the suggestion that $\operatorname{Lp}(a)$ delivers cholesterol to proliferating cells at sites of vascular injury. Excess local $\mathrm{Lp}(a)$ at injury sites may be oxidized and taken up by macrophages, and contribute to foam-cell formation within plaques $^{15}$. The present work provides little support for this cholesterol-delivery hypothesis, rather supporting the view that $\operatorname{apo}(a)$, independent of its lipid component, perhaps inhibits clot lysis and that this can initiate the activation and accumulation of lipid-laden macrophages and smooth muscle cells.

Apo $(a)$ shows extraordinary size variation, assuming a relative molecular mass between 280,000 and 830,000 . More than twenty size alleles are inherited in a co-dominant fashion and result from variation in the number of kringle IV repeats in the gene. The plasma concentration of $\operatorname{Lp}(a)$ is inversely correlated with allele size. Ninety per cent of the variability in $\mathrm{Lp}(a)$ concentration in the plasma is attributable to the $\operatorname{Lp}(a)$ locus. Much, but not all of this is due to size variation $^{16}$.

Until now, the promoter of the gene has eluded identification. The reason is that $\operatorname{apo}(a)$ and plasminogen and all other closely related genes reside on chromosome 6. Complementary DNA probes from the $5^{\prime}$ end of apo $(a)$ DNA reveal at least six distinct genomic fragments showing more than 90 per cent nucleotide homology over more than a kilobase. Three of these have been identified as belonging to plasminogen, and are termed plasminogen-related genes $\mathrm{A}$ and $\mathrm{B}^{17}$; the latter is expressed in tumours $^{18}$. The other three sequences may be part of apo(a)-like genes, and/or pseudogenes produced by duplication. At the meeting in Shizuoka, Lawn reported that a region 1 kilobase long from the $5^{\prime}$ flanking regions of all six of these loci can direct the transcription of a luciferase reporter gene in HepG2 cells, so that the products attributable to these promoters and the effect of transcription on Lp $(a)$ blood levels should soon be discovered.

The identification of the apo $(a)$ gene promoter(s) has another importance. There is no effective treatment yet for reducing elevated blood $\mathrm{Lp}(a)$ concentration. The known hypolipidaemic drugs (HMG-CoA reductase inhibitors, bile acid sequestrants, fibric acid derivatives, probucol) and diet have little effect on $\operatorname{Lp}(a)$ concentrations. Nicotinic acid alone or in combination with neomycin can reduce $\operatorname{Lp}(a)$, but unpleasant flushing and hepatic and ototoxicity militate against the long-term use of these drugs. However we are entering a new era in which gene promoters attached to marker genes are being screened in order to discover compounds that interfere with transcription. This is made possible by the development of advanced robotics and computing, and recombinant DNA methods for generating huge libraries of compounds. Lipoprotein $(a)$, apoA-I, the microsomal triglyceride transfer protein and their genes are prime targets for the pharmaceutical industry.

James Scott is in the Department of Medicine, Royal Postgraduate Medical School, Hammersmith Hospital, Du Cane Road, London W12 ONN, UK.

\footnotetext{
1. Lawn, R. M., Wade, D. P.. Hammer, R. E., Verstuyft, G. \& Rubin, E. M. Nature 360, 670-672 (1992)

2. Brown, M. S. \& Goldstein, J. L. Cell 71. 187 (1992),

3. Plump. A. S. et al. Cell 71, 343-353 (1992)

4. Zhang, S. H.. Reddick, R. L., Piedrahita, J. A. \& Maeda, N. Science 258, 468-471 (1992)

N. Science 258, 468-471 (1992).
5. Rubin. E. et al. Nature 353 265-267 (1991).

6. Hofmann, S. L. et al. Science 239, 1277-1281 (1988)

7. Shimano, H. et al. Proc. Natn. Acad. Sci. U.S.A. 89 1750-1754 (1992)

8. Scott, J. Br. Med. J. 303, 663-664 (1991)

9. Talmud, P. J. et al. J. clin. Invest. 82, 1803 (1988)

10. Chiesa G. et al J biol Chem (in the press).

11. White, A. L., Rainwater, D. L. \& Lanford, R. E. J. Lipid Res. (in the press)

12. Law, A. \& Scott, J. J. Lipid Res. 31, 1109 (1990) 13. Yang, C.-Y. et al. Arteriosclerosis 9, 96-108 (1989). 14. Wetterau, J. R. et al. Science 258, 999-1001 (1992)

15. Zioncheck, T. F Powell L. M Rice G. C Eaton. D. L. \& Lawn. R. M. J. clin. Invest. 87, 767-771 (1991). 16. Boerwinkle, E. et al. J. clin. Invest. 90, 52-60 (1992). 17. Ichinose. A. Biochemistry 31, 3113-3118 (1992). 18. Weissbach, L. \& Treadwell, B. Biochim. biophys. Res. Commun. 186, 1108-1114 (1992).
}

\section{Travelling light}

DAEDALUS once invented a steam lawnmower that burnt its own cuttings. The longer and thicker the grass, the more copious its fuel supply and the more vigorously it worked; and when its task was completed it stopped automatically. He now links this idea to his plan of last week for an agricultural diesel engine that burns powdered plant waste. It carries a cryogenic system to pulverize the waste at liquid-air temperature, and to condense its exhaust to a slurry of plant ash, water and nitrates of combustion. This is returned to the soil as fertilizer. Daedalus sees this principle as the basis of a whole new ecologically benign transport system.

Imagine, he says, a road covered not with concrete but with grass. It would probably need a concrete meshwork of some sort to support vehicle wheels, but most of its area would be under cultivation. A vehicle travelling along the road could shave a small amount from the grass, and burn it for fuel. By the time the next vehicle came along, the grass would have grown again.

Such a road could power light traffic indefinitely, at no cost. If the grass were to trap solar energy with a photosynthetic efficiency as great as $\mathbf{1 0}$ per cent, then in full sunlight the agricultural road could fuel about one vehicle every ten seconds. In practice, a vehicle every few minutes might be the upper limit. This could be increased by wide traffic-lanes, enabling each vehicle to harvest a different track of grass. The system is even better suited for powering a light railway. Railway traffic rates are much lower than those of a road, and the energy needed to carry a given weight at speed is much less.

Grass is quite a good plant for this Job. It can be flattened by a wheel and springs back undismayed; it survives repeated cropping by lawnmowers or cows; it can hold its own against weeds, and will dominate a mixed, equilibrium ecosystem. DREADCO biologists would prefer a plant with a higher photosynthetic efficiency, but the best performers in this category seem to be algae like Chlorella which flourish in water. So Daedalus also plans to adapt his scheme for transport on a system of deliberately eutrophic canals, possibly the receivers in a distributed sewage system. Always green, and scummy with algae, such canals could power a steady stream of boats that sucked in and burnt the floating plant material.

This elegant arrangement is clearly unsuited to intensively industrial societies. Daedalus offers it as a contribution to the eco-dream of a sustainable, postindustrial society, such as may develop in the Third World when the oil has run out. David Jones 